\title{
A Comprehensive Study on the Reason of Low Enthusiasm for Master Students Majored in Basic Mathematics
}

\author{
Qi Gao, Hailun Fu \\ School of Mathematical Sciences, Shandong Normal University, Jinan, China \\ Email: dubujinghong@163.com
}

How to cite this paper: Gao, Q. and Fu, H.L. (2017) A Comprehensive Study on the Reason of Low Enthusiasm for Master Students Majored in Basic Mathematics. Open Journal of Social Sciences, 5, 216-226. https://doi.org/10.4236/jss.2017.54019

Received: March 17, 2017

Accepted: April 27, 2017

Published: April 30, 2017

Copyright (c) 2017 by authors and Scientific Research Publishing Inc. This work is licensed under the Creative Commons Attribution International License (CC BY 4.0).

http://creativecommons.org/licenses/by/4.0/ (c) (i) Open Access

\begin{abstract}
With the development of the society, demands for talents in various countries are gradually increasing. Graduate students are an integral proportion of the national high quality talents, and therefore their learning situation is closely related with the development of our country. As a result, we argue that it is not only important but necessary to study the current situation of them. In the previous work on the basic mathematics graduate students, we have come to the conclusion that their learning enthusiasm is not high. To understand the main cause of this problem, we try to perform a deep investigation on possible reasons and factors in this paper. More specifically, we first classify the reasons that may influence the enthusiasm of graduate students into two categories, i.e., internal reasons and external reasons. Then we further refine them into 10 finegrained aspects and conduct detailed discussion for each aspect. Finally, we draw our conclusions on the basis of the classification and discussion.
\end{abstract}

\section{Keywords}

Master Student Enthusiasm, Basic Mathematics, Reasons and Factors

\section{Introduction}

\subsection{Background}

The cultivation of talents promotes the development and progress of society, and the development and progress of society need to train more talents. The major contributor to society's stunning ignorance of science has been our educational system [1]. In order to cultivate more talents for social development, we must first understand their current situation. As an indispensable member of the state, the current situation of graduate study is closely related to the development of the world. As mathematics is a discipline with strong and rigorous logic as well 
as a wide range of application, the development of mathematics will inevitably affect the development of society [2]. Therefore, it is important and necessary to study the current situation and the main causes of the low enthusiasm for master students of the basic mathematics major. It should be clear that there are largebodies of evidence from a lot of various fields supporting the effectiveness of high learning enthusiasm [3] [4] [5] [6]. Based on the investigation of 15 master students in Shandong Normal University, we come to the conclusion that their learning enthusiasm is not high. Now we will use the way of questionnaire to explore the reasons why their learning enthusiasm is relatively low.

\subsection{Significance of the Study}

Learning enthusiasm is the driving force to stimulate students to learn, keep learning, and guide learning to a certain goal. It is usually reflected in the student's attention to the state of learning, emotional tendencies and perseverance and so on [7]. The learning enthusiasm of the students has a great influence on their future study and life. The literal meaning of "attribution" is to seek the cause of the event. In psychology domain, it means to find the root cause of the special cognitive activity. There may be many reasons for the existence of a problem, but only after clarifying the causes of a problem can we develop more effective measures to address this problem [8]. Therefore, it is meaningful to study the attribution of low enthusiasm of master students. In theory, it is helpful to enrich the vacancy of the relevant theories and it plays a positive role in the development and perfection of math ematicale ducation psychology and social psychology. In practice, it has a positive impact on the formation of good learning habits. In addition, it can also help improve academic performance, promote the healthy development of students and develop a positive attitude towards life.

\section{Process of the study}

\subsection{Problem Analysis}

Learning enthusiasm refers to the serious and diligent, active and stubborn psychological state of students in learning activities. Learning enthusiasm is usually reflected by the attention to learn, emotional tendencies and perseverance.

In order to understand the main reasons why the current mathematics majors are not so enthusiastic about learning, we classified the reasons into two categories: internal and external reasons. The rationale behind is that the more detailed categories we have the more accurate analysis results we will get. The internal reasons can be refined into 5 aspects: the interest in learning content (ILC), the awareness of the importance of professional courses (AIPC), the expectation of getting good grades (EGGG), the desire to get attention and the sense of accomplishment (DASA), and the negative consequences of being afraid of not being positive (NCBP). The external reasons can be divided into 5 aspects: the requirements of teachers (RT), the requirements of parents (RP), the requirements of school (RS), class awards (CA) and employment (EM). 


\subsection{Questionnaire Development}

According to the above analysis, we compiled a questionnaire containing 27 single topics, with the first 16 as a group, to examine the internal causes, and the latter 11 questions as a group, to investigate the external causes (Table 1 and Table 2). In the internal causes, the topics are divided into five groups: 1 to 3 as a group, 4 and 5 as a group, 9 and 10 as a group, 6, 7, 8, 11 as a group individually,12 to 16 as a group, which corresponds to each sub-catalogues. For the external reasons, the topics will also be divided into 5 groups: 19, 20, 21, 22, 26 as a group, to examine the requirements of teachers. Eighteenth and 25 as a group, to examine the requirements of parents. Seventeenth and 27 as a group, to examine the requirements of school. Question twenty-third as a group, to examine class awards and Question twenty-fourth as a group, to examine employment. Each question has 5 answers (see Appendix for the questionnaire).

\subsection{Distribution and Collection of Questionnaires}

After the completion of the questionnaire, they were distributed to each of the graduate students in the basic mathematics of Shandong Normal University. They finished the questionnaire in 30 minutes. A total of 15 questionnaires were distributed and 15 valid questionnaires were returned. Note that all participants hold a bachelor degree and are in their first or second year of the mater.

\section{Questionnaire Analysis}

\subsection{Results of the Study}

After collecting the questionnaire, the data was calculated. The process was as follows: Firstly, each student's answer was completed in the Tables 3-12. Then recording the number of each option and the proportion of each option. Next analyzing the proportion of each topic. Finally we drew conclusions of each topic. The findings of the questionnaire were as follows:

\subsubsection{Internal Causes}

1) Most students are interested in learning content

From the first question, we can conclude that $93.33 \%$ of students are interested in the study of current professional courses. From the second question, we can conclude that $80 \%$ of students are interested in the learning of knowledge.

Table 1. Internal Questions and Sub-catalogues.

\begin{tabular}{cc}
\hline Questions & Sub-catalogues \\
\hline $1,2,3$ & ILC \\
4,5 & AIPC \\
9,10 & EGGG \\
$6,7,8,11$ & DASA \\
$12,13,14,15,16$ & NCBP \\
\hline
\end{tabular}


Table 2. External Questions and Sub-catalogues.

\begin{tabular}{cc}
\hline Questions & Sub-catalogues \\
\hline $19,20,21,22,26$ & RT \\
18,25 & RP \\
17,27 & RS \\
23 & CA \\
24 & EM \\
\hline
\end{tabular}

Table 3. Number and percentage of questions 1, 2, and 3.

\begin{tabular}{ccccccccccc}
\hline \multirow{2}{*}{ question } & \multicolumn{2}{c}{$\mathrm{A}$} & \multicolumn{2}{c}{$\mathrm{B}$} & \multicolumn{2}{c}{$\mathrm{C}$} & \multicolumn{2}{c}{$\mathrm{D}$} & \multicolumn{2}{c}{$\mathrm{E}$} \\
\cline { 2 - 11 } & No. & P.c. & No. & P.c. & No. & P.c. & No. & P.c. & No. & P.c. \\
\hline 1 & 0 & 0 & 6 & 40 & 8 & 53.33 & 1 & 6.67 & 0 & 0 \\
2 & 0 & 0 & 5 & 33.33 & 7 & 46.67 & 3 & 20 & 0 & 0 \\
3 & 0 & 0 & 1 & 6.67 & 11 & 73.33 & 3 & 20 & 0 & 0 \\
\hline
\end{tabular}

Table 4. Number and percentage of questions 4 and 5.

\begin{tabular}{cccccccccccc}
\hline \multirow{2}{*}{ question } & \multicolumn{2}{c}{$\mathrm{A}$} & \multicolumn{2}{c}{$\mathrm{B}$} & \multicolumn{2}{c}{$\mathrm{C}$} & \multicolumn{2}{c}{$\mathrm{D}$} & \multicolumn{2}{c}{$\mathrm{E}$} \\
\cline { 2 - 11 } & No. & P.c. & No. & P.c. & No. & P.c. & No. & P.c. & No. & P.c. \\
\hline 4 & 4 & 26.67 & 8 & 53.33 & 3 & 20 & 0 & 0 & 0 & 0 \\
5 & 2 & 13.33 & 5 & 33.33 & 6 & 40 & 2 & 13.33 & 0 & 0 \\
\hline
\end{tabular}

Table 5. Number and percentage of questions 9 and 10.

\begin{tabular}{cccccccccccc}
\hline \multirow{2}{*}{ question } & \multicolumn{2}{c}{$\mathrm{A}$} & \multicolumn{2}{c}{$\mathrm{B}$} & \multicolumn{2}{c}{$\mathrm{C}$} & \multicolumn{2}{c}{$\mathrm{D}$} & \multicolumn{2}{c}{$\mathrm{E}$} \\
\cline { 2 - 11 } & No. & P.c. & No. & P.c. & No. & P.c. & No. & P.c. & No. & P.c. \\
\hline 9 & 3 & 20 & 9 & 60 & 3 & 20 & 0 & 0 & 0 & 0 \\
10 & 1 & 6.67 & 8 & 53.33 & 3 & 20 & 2 & 13.33 & 1 & 6.67 \\
\hline
\end{tabular}

Table 6. Number and percentage of questions $6,7,8$, and 11 .

\begin{tabular}{ccccccccccc}
\hline \multirow{2}{*}{ question } & \multicolumn{2}{c}{$\mathrm{A}$} & \multicolumn{2}{c}{$\mathrm{B}$} & \multicolumn{2}{c}{$\mathrm{C}$} & \multicolumn{2}{c}{$\mathrm{D}$} & \multicolumn{2}{c}{$\mathrm{E}$} \\
\cline { 2 - 10 } & No. & P.c. & No. & P.c. & No. & P.c. & No. & P.c. & No. & P.c. \\
\hline 6 & 3 & 20 & 8 & 53.33 & 4 & 26.67 & 0 & 0 & 0 & 0 \\
7 & 1 & 6.67 & 8 & 53.33 & 5 & 33.33 & 0 & 0 & 1 & 6.67 \\
8 & 1 & 6.67 & 9 & 60 & 4 & 26.67 & 0 & 0 & 1 & 6.67 \\
11 & 2 & 13.33 & 7 & 46.67 & 5 & 33.33 & 0 & 0 & 1 & 6.67 \\
\hline
\end{tabular}

From the third question, we can conclude that $73.33 \%$ of the students feel generally to the homework assigned by the teachers and $20 \%$ of students are not interested in doing homework. In conclusion, we can get that most students are interested in learning content. Thus interested in learning content is not a factor to affect the basic math majors' learning enthusiasm. 
Table 7. Number and percentage of questions $12,13,14,15$, and 16.

\begin{tabular}{ccccccccccc}
\hline & \multicolumn{2}{c}{ A } & \multicolumn{2}{c}{ B } & \multicolumn{2}{c}{ C } & \multicolumn{2}{c}{ D } & \multicolumn{2}{c}{ E } \\
\cline { 2 - 10 } question & No. & P.c. & No. & P.c. & No. & P.c. & No. & P.c. & No. & P.c. \\
\hline 12 & 1 & 6.67 & 4 & 26.67 & 9 & 60 & 1 & 6.67 & 0 & 0 \\
13 & 1 & 6.67 & 5 & 33.33 & 5 & 33.33 & 2 & 13.33 & 2 & 13.33 \\
14 & 1 & 6.67 & 2 & 13.33 & 5 & 33.33 & 6 & 40 & 1 & 6.67 \\
15 & 1 & 6.67 & 6 & 40 & 5 & 33.33 & 2 & 13.33 & 1 & 6.67 \\
16 & 0 & 0 & 3 & 20 & 3 & 20 & 5 & 33.33 & 4 & 26.67 \\
\hline
\end{tabular}

Table 8. Number and percentage of questions 19, 20, 21, 22, and 26.

\begin{tabular}{cccccccccccc}
\hline \multirow{2}{*}{ question } & \multicolumn{2}{c}{$\mathrm{A}$} & \multicolumn{2}{c}{$\mathrm{B}$} & \multicolumn{2}{c}{$\mathrm{C}$} & \multicolumn{2}{c}{$\mathrm{D}$} & \multicolumn{2}{c}{$\mathrm{E}$} \\
\cline { 2 - 11 } & No. & P.c. & No. & P.c. & No. & P.c. & No. & P.c. & No. & P.c. \\
\hline 19 & 0 & 0 & 2 & 13.33 & 8 & 53.33 & 5 & 33.33 & 0 & 0 \\
20 & 0 & 0 & 4 & 26.67 & 5 & 33.33 & 6 & 40 & 0 & 0 \\
21 & 2 & 13.33 & 5 & 33.33 & 4 & 26.67 & 3 & 20 & 1 & 6.67 \\
22 & 0 & 0 & 3 & 20 & 4 & 26.67 & 6 & 40 & 2 & 13.33 \\
26 & 0 & 0 & 3 & 20 & 5 & 33.33 & 7 & 46.67 & 0 & 0 \\
\hline
\end{tabular}

Table 9. Number and percentage of questions 18 and 25.

\begin{tabular}{cccccccccccc}
\hline \multirow{2}{*}{ question } & \multicolumn{2}{c}{$\mathrm{A}$} & \multicolumn{2}{c}{$\mathrm{B}$} & \multicolumn{2}{c}{$\mathrm{C}$} & \multicolumn{2}{c}{$\mathrm{D}$} & \multicolumn{2}{c}{$\mathrm{E}$} \\
\cline { 2 - 11 } & No. & P.c. & No. & P.c. & No. & P.c. & No. & P.c. & No. & P.c. \\
\hline 18 & 0 & 0 & 5 & 33.33 & 5 & 33.33 & 2 & 13.33 & 3 & 20 \\
25 & 0 & 0 & 2 & 13.33 & 5 & 33.33 & 3 & 20 & 5 & 33.33 \\
\hline
\end{tabular}

Table 10. Number and percentage of questions 17 and 27.

\begin{tabular}{cccccccccccc}
\hline \multirow{2}{*}{ question } & \multicolumn{2}{c}{$\mathrm{A}$} & \multicolumn{2}{c}{$\mathrm{B}$} & \multicolumn{2}{c}{$\mathrm{C}$} & \multicolumn{2}{c}{$\mathrm{D}$} & \multicolumn{2}{c}{$\mathrm{E}$} \\
\cline { 2 - 11 } & No. & P.c. & No. & P.c. & No. & P.c. & No. & P.c. & No. & P.c. \\
\hline 17 & 1 & 6.67 & 7 & 46.67 & 6 & 40 & 0 & 0 & 1 & 6.67 \\
27 & 0 & 0 & 4 & 26.67 & 3 & 20 & 5 & 33.33 & 3 & 20 \\
\hline
\end{tabular}

Table 11. Number and percentage of question 23.

\begin{tabular}{ccccccccccc}
\hline \multirow{2}{*}{ question } & \multicolumn{2}{c}{$\mathrm{A}$} & \multicolumn{2}{c}{ B } & \multicolumn{2}{c}{$\mathrm{C}$} & \multicolumn{2}{c}{$\mathrm{D}$} & \multicolumn{2}{c}{$\mathrm{E}$} \\
\cline { 2 - 11 } & No. & P.c. & No. & P.c. & No. & P.c. & No. & P.c. & No. & P.c. \\
\hline 23 & 1 & 6.67 & 9 & 60 & 5 & 33.33 & 0 & 0 & 0 & 0 \\
\hline
\end{tabular}

Table 12. Number and percentage of question 24 .

\begin{tabular}{ccccccccccc}
\hline \multirow{2}{*}{ question } & \multicolumn{3}{c}{ A } & \multicolumn{2}{c}{ B } & \multicolumn{2}{c}{ C } & \multicolumn{2}{c}{ D } & \multicolumn{2}{c}{ E } \\
\cline { 2 - 11 } & No. & P.c. & No. & P.c. & No. & P.c. & No. & P.c. & No. & P.c. \\
\hline 24 & 0 & 0 & 5 & 33.33 & 5 & 33.33 & 3 & 20 & 2 & 13.33 \\
\hline
\end{tabular}


2) Most students are aware of the importance of professional courses

From the fourth question, we can conclude that most of the students are aware of the importance of professional lessons for graduate students during the professional development. From the fifth question, we can conclude that $86.67 \%$ of the students are aware of the importance of professional lessons for future development. To sum up, we can get that most of the students are aware of the importance of professional courses. Thus to aware of the importance of professional courses is not a factor to affect the basic math majors' learning enthusiasm.

3) Most of the students hope to get good grades

From the ninth question, we can conclude that most students realize the importance of good grades for the development of graduate students. From the tenth question, we can conclude that $80 \%$ of students realize that good grades are important to the future development. In conclusion, we can get that most students expect to get good grades. Thus expecting to get good grades is not a factor to affect the basic math majors' learning enthusiasm.

4) Most of the students expect to get attention and get the sense of accomplishment

From the sixth question, we can conclude that the majority of students recognize the importance of teacher's praise. From the seventh question, we can conclude that $93.33 \%$ students think it is important to get the attention and appreciation of classmates; From the eighth question, we can conclude that $93.33 \%$ students think it is important to get respect through positive study. From the 11th question, we can conclude that $93.33 \%$ students think it is important to gain a sense of honor through active study. In summary, we can conclude that most students expect to get attention and get the sense of accomplishment. Thus expecting to get attention and get the sense of accomplishment is not a factor to affect the basic math majors' learning enthusiasm.

5) Most of the students fear that it will bring bad consequences if they are not positive

From the 12th question, we can conclude that $93.33 \%$ of the students fear that they can't get the scholarship. From the 13th question, we can conclude that $73.33 \%$ of the students don't worry about the exam. From the 14 th question, we can conclude that $73.33 \%$ of the students are not too worried about graduation difficulties. From the 15th question, we can conclude that $80 \%$ of the students are worried that they will make the teacher angry if they fail to meet the teacher's demands. From the 16th question, we can conclude that $80 \%$ of the students don't worry that they will be unsocial. To sum up, most of the students fear that it will bring bad consequences if they are not positive. Thus the fear of bringing bad consequences if they are not positive is not a factor to affect the basic math majors' learning enthusiasm.

\subsubsection{External Causes}

1) Demands of teacher are relatively low

From the 19th question, we can conclude that $86.66 \%$ of the students think the teacher's request for homework is loose. From the 20th question, we can 
conclude that $73.33 \%$ of the teachers sometimes ask their students to learn some books or articles related to the profession. From the 21th question, we can conclude that $73.33 \%$ of the tutors require their students to report regularly on the learning situation. From the 22th question, we can conclude that $80 \%$ of students think that their tutor will criticize them if they are not positive. From the 26th question, we can conclude that $80 \%$ of the students think teachers will rarely reward themselves for their active learning. To sum up, most students think the teacher's demands are low. Thus teachers' low demands for students is a factor to affect the basic math majors' learning enthusiasm.

2) The requirement of parents is low

From the 18th question, we can conclude that $66.67 \%$ of the students think that the requirement of parents is low. From the 25th question, we can conclude that $86.67 \%$ of the students think their parents seldom reward themselves for their good grades. To sum up, we can get that the requirement of parents is low. Thus the low requirement of parents is a factor to affect the basic math majors' learning enthusiasm.

3) The school has high requirements for scientific research, but the corresponding rewards are less

From the 17th question, we can conclude that $93.33 \%$ of the students think the school has high requirement for their scientific research achievements. From the 27 th question, we can conclude that $73.33 \%$ of the students think that schools will rarely reward themselves for their positive learning. To sum up, we can get that the school has high requirement for scientific research, but the corresponding rewards are less. Thus the requirement of school is a factor to affect the basic math majors' learning enthusiasm.

4) Most of the students recognize the importance of awards in class

From the 23th question, we can conclude that most of the students think it is important to get awards in the class. In conclusion, we can get that most of the students recognize the importance of awards in class. Thus the awards in class is not a factor to affect the basic math majors' learning enthusiasm.

5) Some students realize that it will sometimes cause difficulties in employment if you have low enthusiasm in studying.

From the 24 th question, we can conclude that $66.67 \%$ of the students think it will be difficult to employment if you are not studying active. In conclusion, we can get that most students realize that it will sometimes cause difficulties in employment if you have low enthusiasm in studying. Thus the requirement of the job is not a factor to affect the basic math majors' learning enthusiasm.

\subsection{Analysis of the Results}

Based on evaluation of the above-mentioned questions we can draw the following conclusions:

For external factors, the teacher's demands, the requirements of the parents and school are the most important factors that affect motivation, while the requirement of work and the awards of class are not the factors to affect the basic 
math majors' learning.

For the internal factors, interest in learning content, awareness of the importance of professional courses, expectations of good results, expectations of attention and achievement and fear of negative consequences are not the factors of learning motivation.

Comparing with internal factors, external factors have a greater impact on motivation. Therefore, in order to improve the enthusiasm of the students, the school, parents and teachers should put reasonable requirements to students and give them enough care and encouragement, so that they can continue to progress and improve.

\section{Concluding Remarks}

In this paper, the method of questionnaire survey is used to study the current status of the learning enthusiasm of basic mathematics major master students and the following conclusions are obtained.

By comparing the external factors with the internal factors, the former has a greater impact on the learning enthusiasm of the master students, while the latter has less influence on them. For the external factors, the teacher's demands, the requirements of the parents and school do have a certain impact on the learning enthusiasm of master students, and the requirements of work and the awards of class are not the factors affecting the learning enthusiasm of basic mathematics. For the internal factors, interest in learning content, awareness of the importance of professional courses, expectations of good results, expectations of attention and achievement and fear of negative consequences are not the factors of learning enthusiasm.

\section{References}

[1] Volpe, E.P. (1984) The Shame of Science Education. Am Zoologist, 24, 433-441. https://doi.org/10.1093/icb/24.2.433

[2] Fu, H.L. and Jia, G.J. (2009) Introduction to Mathematical Thinking Method. Shandong Education Press, Jinan.

[3] Briscoe, C. and La Master, S.U. (1991) Meaningful Learning in College Biology through Concept Mapping. The American Biology Teacher, 53, 214-219. https://doi.org/10.2307/4449272

[4] McDermott, L.C. and Shaffer, P.S. (1992) Research as a Guide for Curriculum Development: An Example from Introductory Electricity. Part I: Investigation of Student Understanding. American Journal of Physics, 60, 994-1003. https://doi.org/10.1119/1.17003

[5] Towns, M.H. and Grant, E.R. (1997) "I Believe I Will Go out of This Class Actually Knowing Something": Cooperative Learning Activities in Physical Chemistry. Journal of Research in Science Teaching, 34, 819-835. https://doi.org/10.1002/(SICI)1098-2736(199710)34:8<819::AID-TEA5>3.0.CO;2-Y

[6] Wosilait, K., Heron, P.L., Shaffer, P.S. and McDermott, L.C. (1998) Development and Assessment of a Research-Based Tutorial on Light and Shadow. American Journal of Physics, 66, 906-913. https://doi.org/10.1119/1.18988

[7] Xu, F.Y. and Song, X.H. (2003) A Study on the Factors Affecting College Students' 
Learning Motivation and the Countermeasures. Course Education Research, Huhehaote.

[8] Liu, Y.F. (1998) Attribution Theory and Its Application. Shandong People's Publishing House, Jinan. 


\section{Appendix}

Detailed contents of the questionnaire is given below. Mathematics Major

Dear classmates:

In order to understand the reasons for the low enthusiasm of the current basic mathematics master students, we use an anonymous way to list some questions. Note that your answers are not treated as a basis for any assessment of you. Please read the questions carefully and choose an answer for each question. Please tick in the appropriate answer. Thank you for your cooperation.

1. Are you interested in the current knowledge of the subject?
A. Very much
B. A little
C. Just so so
D. Not very interested
E. Not interested

2. Are you interested in learning in class?
A. Very much
B. A little
C. Just so so
D.Not very interested
E. Not interested

3. Are you interested in the homework assigned by the teacher?
A. Very much
B. A little
C. Just so so
D. Not very interested
E. Not interested

4. Do you think it is important for the professional development of graduate students to study professional knowledge?
A. Very important
B. A little
C. Just so so
D. Not very important
E. Not important

5. Do you think the current knowledge of professional courses will be helpful to the future development?
A. It is very helpful
B. it does have some help
C. Just so so
D. It doesn; t help much
E. It doesn't have any help

6. Do you think the teacher's praise is important?
A. Very important
B. A little
C. Just so so D. Not very important
E. Not important

7. Do you think the appreciation of other students is important?
A. Very important
B. A little
C. Just so so
D. Not very important
E. Not important

8. Do you think it is important to gain the respect of others through active learning?
A. Very important
B. A little
C. Just so so
D. Not very important
E. Not important

9. Do you think it is important for you to get good grades in the development of graduate students?
A. Very important
B. A little
C. Just so so
D. Not very important
E. Not important

10. Do you think it is important for future development to get good grades?
A. Very important
B. A little
C. Just so so
D. Not very important
E. Not important

11. Do you think it is important to gain a sense of honor through active learning?
A. Very important
B. A little
C. Just so so
D. Not very important
E. Not important

12. Are you worried that you can't get a scholarship?
A. Always
B. Most occasions
C. Sometimes
D. Seldom
E. Never

13. Are you worried about the exam?
A. Always
B. Most occasions
C. Sometimes
D. Seldom
E.Never

14. Are you worried about graduation?
A. Always
B. Most occasions
C. Sometimes
D. Seldom
E. Never

15. Do you worry about failing to meet the teacher's demands, which makes the teacher angry?
A. Always
B. Most occasions
C. Sometimes
D. Seldom
E. Never

16. Are you worried that you will be unsocial?
A. Always
B. Most occasions
C. Sometimes
D. Seldom
E. Never

17. Does the school have a high demand for research papers?
A. The demand is very high
B. The demand is high
C. Just so so
D. The demand is not so high $\quad$ E. The demand is quiet low
18. Will your parents ask you to study hard?
A. The demand is very high
B. The demand is high
C. Just so so
D. The demand is not so high E. The demand is quiet low
19. Does the teacher ask you to finish your homework in time? 


\section{Continued}
A. The demand is very high $B$. The demand is high
C. Just so so
D. The demand is not so high $\quad$ E. The demand is quiet low

20. Does the teacher ask you to learn some professional books or articles?
A. Always
B. Most occasions
C. Sometimes
D. Seldom
E.Never

21. Does the teacher ask you to report on your study regularly?
A. Always
B. Most occasions
C. Sometimes
D.Seldom
E.Never

22. Will the teacher criticize you if you are not active in studying?
A. Always
B. Most occasions
C. Sometimes
D. Seldom
E. Never

23. Is it important for you to get awards in the class?
A. Very important
B.A little
C. Just so so
D. Not very important
E. Not important

24. Do you think it is difficult to get a job if you are not studying hard?
A. Always
B. Most occasions
C. Sometimes
D. Seldom
E. Never

25 . Will your parents reward you for your good grades?
A. Always
B. Most occasions
C. Sometimes
D. Seldom
E. Never

26. Will the teacher praise you for your positive study?
A. Always
B. Most occasions
C. Sometimes
D. Seldom
E. Never

27. Will the school reward you for your positive learning?

\section{Submit or recommend next manuscript to SCIRP and we will provide best} service for you:

Accepting pre-submission inquiries through Email, Facebook, LinkedIn, Twitter, etc. A wide selection of journals (inclusive of 9 subjects, more than 200 journals)

Providing 24-hour high-quality service

User-friendly online submission system

Fair and swift peer-review system

Efficient typesetting and proofreading procedure

Display of the result of downloads and visits, as well as the number of cited articles

Maximum dissemination of your research work

Submit your manuscript at: http://papersubmission.scirp.org/

Or contact jss@scirp.org 